\title{
Evaluation of the Root and Canal Morphology of Maxillary Permanent Molars and the Incidence of the Second Mesiobuccal Root Canal in Greek Population Using Cone-beam Computed Tomography
}

\author{
Georgia E. Nikoloudaki ${ }^{*}$, Taxiarchis G. Kontogiannis and Nikolaos P. Kerezoudis
}

Department of Endodontics, Dental School, University of Athens, Greece

\begin{abstract}
Objectives: }}$ Cone-Beam Computed Tomography is an alternative imaging technique which has been recently introduced in the field of Oral \& Maxillofacial Radiology. It has rapidly gained great popularity among clinicians due to its ability to detect lesions and defects of the orofacial region and provide three-dimensional information about them. In the field of Endodontics, CBCT can be a useful tool to reveal tooth morphology irregularities, additional root canals and vertical root fractures. The objective of this study is to evaluate the root and root canal morphology of the maxillary permanent molars in Greek population using Cone-Beam Computed Tomography. Materials and Methods: 273 cone-beam computed tomography (CBCT) images were examined. The number of roots and root canals of the first and second maxillary molars were evaluated. Root canal configuration was classified according to Weine's classification by two independent examiners and statistical analysis was performed. Results: A total of 812 molars (410 first and 402 second ones) were evaluated. The vast majority of both first and second molars had three roots (89.26\% and $85.07 \%$, respectively). Most first molars had four canals, while most second molars had three. In the mesiobuccal roots, one foramen was recorded in $80.91 \%$ of all teeth. Other rare morphologic variations were also found, such as fusion of a maxillary second molar with a supernumerary tooth. Conclusion: Within the limitations of this study, it can be concluded that more attention should be given to the detection of additional canals during root canal treatment in maxillary permanent molars. Towards this effort, CBCT can provide the clinician with supplemental information about the different root canal configurations for successful Root Canal Treatment.
\end{abstract}

Keywords: Cone-beam computed tomography, Greek population, maxillary permanent molars, mesiobuccal root, root and canal morphology.

\section{INTRODUCTION}

Complete and thorough chemomechanical debridement of the root canal system is pivotal for the optimal outcome of the root canal treatment. The clinician should be aware of the possible root canal configurations and the presence of additional canals, which are of vital importance to the complete instrumentation and disinfection of the root canal system [1, $2]$, thus minimizing the risk of treatment failure $[3,4]$.

Numerous studies have been conducted about the morphological variations of maxillary permanent molars, emphasizing the presence of a second mesiobuccal canal in the mesial root. The majority of maxillary first molars $(95.9 \%)$ present 3 roots [5]. The incidence of a second mesiobuccal root canal in the mesial root varies between $26 \%$ [6] and $93.5 \%$ [7]. This variation can be attributed to the different methods that were used by the researchers. Other factors may contribute as well: For example the incidence of two canals in laboratory studies is higher $(60.5 \%)$ to that reported in clinical studies (54.7\%) [5]. Taken together, it can be concluded that the incidence of the second canal (MB2) in

*Address correspondence to this author at the 22 Alexioupoleos Av., Argyroupoli, Athens, Greece, PC: 16452; Tel: +30 6932891706;

E-mail: nikgogo@dent.uoa.gr the mesial root is higher than $50 \%$. Other variations that have been reported in this type of tooth group include the presence of a third canal in the mesial root [8], a second canal in the palatal root [9], and two individual palatal roots (mesiopalatal and distopalatal) with their own separate canals [10]. Moreover, C-shaped configuration [11] has also been reported, as well as root fusion of two or more roots [5].

Many methods have been used to evaluate the inner morphology of a root over the years. Some commonly used in vitro methodologies include various sectioning techniques (sectioning of the root perpendicular or vertically to the long axis of the tooth), root canal impression using low viscosity resin [12] along with root canal staining and tooth clearing $[1,13]$. A main drawback of these techniques is that the samples are irreversibly destructed, thus the results cannot be reproduced and further evaluated. Furthermore, conventional radiographic images both in vivo $[14,15]$ and ex vivo $[16$, 17] can provide valuable information about tooth anatomic variations. More recently, clinical studies evaluate the incidence of additional canals under magnification using loupes or dental operating microscope and by analyzing clinical patients' records or previously treated teeth [18].

The above mentioned techniques are unable to reveal in detail the irregularities of the root canal system owing to their inherent limitations. Although periapical radiographic images provide an adequate amount of information in the 
everyday clinical practice, their interpretation can be perplexed by several factors such as the regional anatomic landmarks or superimposition of adjacent teeth and hard tissues of the orofacial region. Due to the two-dimensional depicting potential and the possible geometric distortion of the image, many three-dimensional anatomic irregularities may be concealed $[19,20]$. Recently, cone beam-computed tomography (CBCT) imaging techniques offer an effective way to overcome these limitations. This is feasible by constructing detailed three-dimensional images of the teeth and the surrounding dentoalveolar structures, thus providing useful information for diagnosis and treatment planning before or during root canal treatment and surgical endodontic procedures.

Many studies have been conducted in order to analyze the inner anatomic variations of maxillary molars using CBCT technology. However, there are no reports on the root and canal configurations of maxillary permanent molars in Greek population. The aim of this study is to evaluate the root canal morphology of the first and second maxillary molars in the Greek population using CBCT imaging.

\section{MATERIALS AND METHODS}

A total number of 273 CBCT images were obtained from patients who visited a private radiologic clinic in Athens, Greece, requiring tomographic examination as part of their dental examination, diagnosis or treatment planning. The study was approved and Ethical Clearance was obtained. Patients' gender and age were recorded in a database along with their signed informed consent form.

Teeth were selected in order to fulfill the following inclusion criteria:

1. First and second maxillary permanent molars

2. With no previous root canal treatment

3. With fully developed roots and mature apices

Exclusion criteria included teeth with:

1. Open apices

2. Root resorption

3. Calcification or extensive coronal restorations.

Moreover, tomographic images of poor quality or artifacts were also excluded.

Finally, 812 teeth met the above criteria, 410 maxillary first and 402 maxillary second molars.

The CBCT images were taken by using the NEWTOM VGI (QR, Verona, Italy) operated at $110 \mathrm{kV}$ with a scanning time of 17 seconds (X-ray emission time 5,4 seconds) with field of view $12 \times 8$ in high resolution mode and a voxel size of $0,125 \mathrm{~mm}$. The reconstruction of the images was made from the axial raw data images and with a slice thickness of $0,5 \mathrm{~mm}$. The CBCT images were analyzed with the NNT software (version 2.21, QR 2001-2009, QR srl, Verona, Italy), while the contrast and brightness of the images were adjusted in order to ensure optimal visualization by using the image-processing tool in the software.

All teeth were analyzed by using 3 planes (sagittal, axial, and coronal), and the following anatomic features were evaluated and recorded:
1. Number of roots and their morphology

2. Number of canals per root

3. Presence of two separate apical foramina (Weine Type III) or two canals that joined to exit at a single foramen (Weine Type II) [21]

All images and features were independently assessed by an endodontist and a radiologist and any disagreement between them was discussed until a consensus was reached.

\section{Statistical Analysis}

Differences between the respective features of first and second maxillary molars were analyzed with Yate's chi square test (significance level $\mathrm{p}<0.05$ ), using SPSS Statistics 18.0 software (SPSS, Inc., Chicago, IL, USA).

\section{RESULTS}

The distribution of patients according to their age was as follows: 8 patients $(2.93 \%)$ were between 18 and 20 years old; $46(16.85 \%)$ were between 21 and 35 years old; 107 (39.2\%) were between 36 and 50 years old; $87(31.87 \%)$ were between 51 and 65 years old and finally, $25(9.15 \%)$ were between 66 and 80 years old. 121 patients $(44.32 \%)$ were males and $152(55.68 \%)$ were females. No difference was recorded between the two genders as regards either the number of roots or the root canals $(\mathrm{p}=0.783)$.

The distribution of the number of roots of the first and second molars is depicted in Table 1. The vast majority of both first and second molars had three roots $(89.26 \%$ \& $85.07 \%$ respectively); there was no statistically significant difference between the two teeth as regards the number of roots $(\mathrm{p}=0.42)$.

The distribution of the number of root canals of the first and second molars is displayed in Table 2. 53.41\% of the first molars had four canals with the fourth one being a second mesiobuccal canal in all cases. The respective frequency among second molars was $40.29 \%$. However, second molars presented more frequently three root canals (49.5\%). A statistically significant difference between the number of root canals of the first and second molar was found $(p<0.001)$; thus, a maxillary first molar is more likely to present four canals than a second one.

Interestingly, some rare morphologic variations were also disclosed in the present study. Two (2) first $(0.49 \%)$ and three (3) second $(0.74 \%)$ molars presented one root and one root canal. Seventeen (17) teeth $(2.09 \%)$ presented fusions of some or all of their roots; most fusions concerned second molars $(81.33 \%)$. There was also one case of a second molar whose distal root was fused with a supernumerary tooth $(0.12 \%)$. Some variations that were recorded are shown in Figs. (1-3).

Canal configuration of the mesiobuccal roots of all teeth was classified according to Weine. The vast majority of mesiobuccal roots $(80.91 \%)$ had either one or two canals that resulted in a single apical foramen. No statistically significant difference was found between first and second molars $(p=0.848)$. 
Table 1. Distribution of first and second molars according to the number of their roots.

\begin{tabular}{|c|c|c|c|c|c|}
\hline 1st molar & 16 & 23 & 366 & 5 & 410 \\
\hline Total & 38 & 56 & 708 & 10 & 812 \\
\hline
\end{tabular}

Table 2. Distribution of first and second molars according to the number of their root canals.

\begin{tabular}{|c|c|c|c|c|c|c|}
\hline & $\mathbf{1}$ canal & 2 canals & 3 canals & 4 canals & 5 canals & Total \\
\hline \hline 1st molar & 16 & 11 & 153 & 219 & 410 \\
\hline 2nd molar & 19 & 11 & 199 & 162 & 11 & 22 \\
\hline Total & 35 & 22 & 352 & 381 & 802 \\
\hline
\end{tabular}

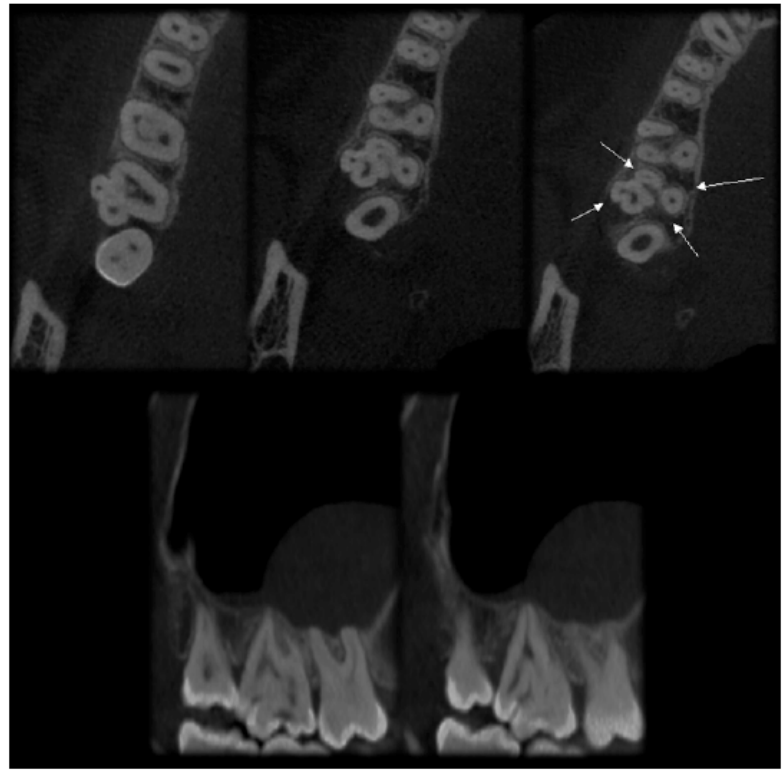

Fig. (1). A case of unilateral permanent maxillary second molar fused with a supernumerary tooth in the distal root, as view in sagittal and axial direction using NNT Viewer Software.

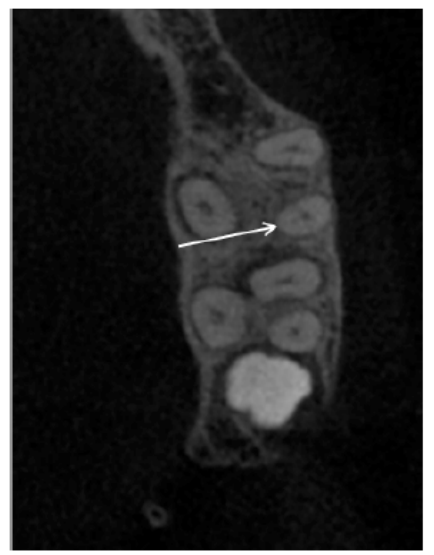

Fig. (2). Case of maxillary first molar with two canals in the distal root as detected in axial section.
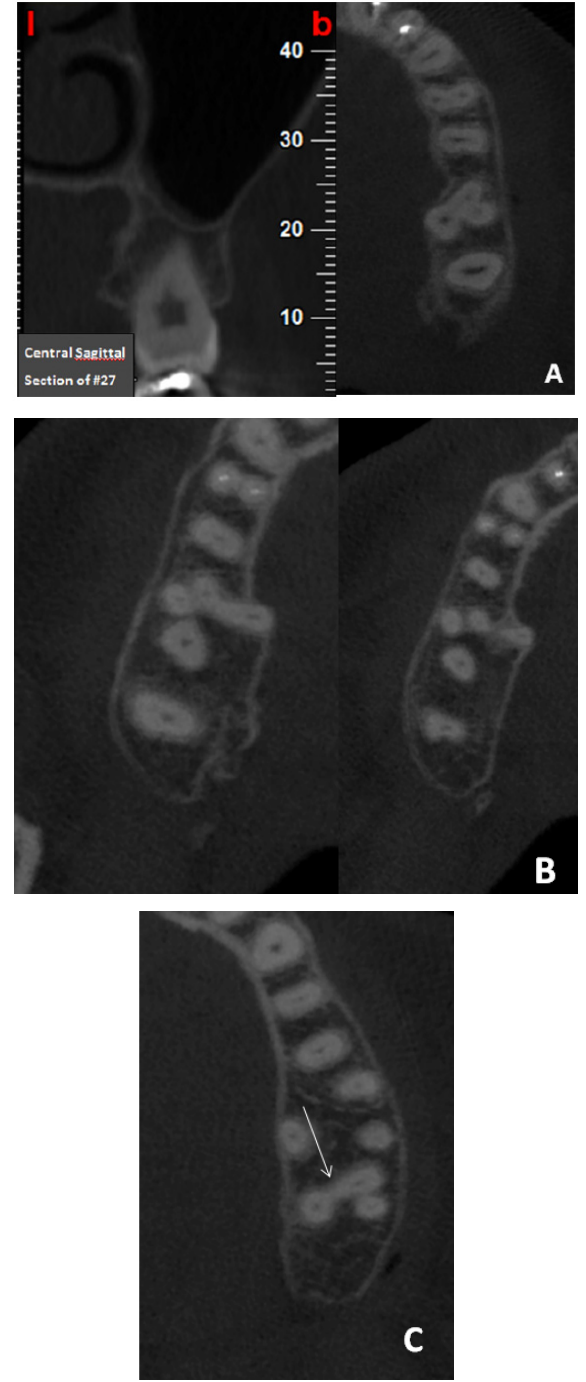

Fig. (3). Cases of maxillary permanent molars with root and root canal variations in sagittal and axial section; (A) a second molar with one root and one root canal, (B) 4-rooted first molar, presenting 3 buccal roots, $(\mathbf{C})$ a second molar with fusion between mesial and palatal root to full lenth. 


\section{DISCUSSION}

CBCT is an essential tool which supplies the clinician with detailed information that conventional intraoral radiographs or panoramic images are not able to, due to its ability to demonstrate anatomic features in three dimensions. It has gained great popularity in the field of Endodontics regarding the identification and the management of perplexing conditions. These include the determination of tooth morphological abnormalities or extra canals in a root as well as the ability to assess intra-operative endodontic treatment mishaps, such as obturating material overextension, instrument separation, identification of root perforations and calcified canals. As far as periapical radiolucencies are concerned, CBCT reveals bone defects of the cancellous bone and cortical bone separately and there is evidence that the prevalence of apical periodontitis is significantly higher when using $\mathrm{CBCT}$, in comparison with conventional periapical radiographs $[22,23]$. CBCT technology has been also proven advantageous in the differential diagnosis of periapical pathosis of non-endodontic origin where the extension of the lesion and its connection to the surrounding anatomical features cannot be determined by the conventional radiographic images. Furthermore, it can be helpful in dentoalveolar trauma cases [24] especially in root fractures [25] luxation displacement and alveolar fractures and in the differential diagnosis of resorption (external, internal and cervical invasive resorption) [26]. Finally, three-dimensional imaging of anatomic features, such as mental foramen, sinus and mandibular canal, is applied in pre-operative case planning in surgical endodontics in order to identify the exact location of root apex/apices and to determine their proximity to adjacent anatomical structures.

In the present study, CBCT was used in order to provide information about the presence or the absence of the MB2 canal in the mesial roots of maxillary permanent molars in Greek population. Recent information from the research field $[27,28]$ provides evidence that $\mathrm{CBCT}$ can be considered as an equally reliable method in detecting the MB2 canal with the gold standard of clinical sectioning the specimens and the state-of-the-art technique of $\mu \mathrm{CT}$.

In our study, it was shown that the majority of upper permanent molars present 3 roots, which is in accordance with previously reported results [5]. The incidence of the MB2 canal in our study was 53\% for the upper first molars and $40.29 \%$ for the second molars, which was within the range of previously reported results $[29,30]$. However, it appears to be higher than reported in previous study in Greece. Sykaras et al. [31] in their in vitro study combined macroscopic observation and evaluation of radiographic images and reported that the incidence of the MB2 canal was $32 \%$. This finding is regarded to be a great indication that the CBCT imaging technique can be a useful tool towards identifying or confirming the presence of additional canals in roots. During the last decade, a vast amount of information regarding the presence of MB2 canal in maxillary molars in a variety of geographical populations has been released [29, 32-37]. The difference in the incidence of the MB2 has been attributed to the impact of the ethnic background on maxillary molar root morphology [37]. Additionally, regarding the configuration of the canal's system in the mesiobuccal root, we found that the majority of MB2 canals merge in a single apical foramen $(80.91 \%)$ with no correlation to the position of the tooth.

However, our study detected a significant correlation regarding the presence of the MB2 canal either at the first or the second molars, with the former being more likely to present four canals than a second one. Moreover, a correlation between gender and the presence of MB2 canal was not found in our study, which is in agreement with previous studies [33].

Additional variations in inner tooth morphology include an extra canal in the distobuccal and palatal root of the first maxillary molar, but they are rarely observed. In our study we found an additional canal in the distal root of only one upper first molar (Fig. 2), conforming to previously reported results which propose the low incidence of these variations $[5,33,35,36]$.

Moreover, we found that maxillary molars in Greek population present fused root in only $2.09 \%$, which is most prevalent in the maxillary second molars $(81.33 \%$ ) (Fig. 3). Studies in Ugandan [38], Irish [39] and Brazlilian [37] population found that the prevalence of root fusion in this tooth group may vary from $7.94 \%$ to $43 \%$. On the other hand, a study in Korean population revealed that the incidence of root fusion is $0.73 \%$ in first molars and $10.71 \%$ in the second maxillary molars, while studies conducted in Burmese [30] and Thai [29] populations found three separate roots in all maxillary first molars. These differences provide an additional indication that the ethnic origin may have a strong impact on the morphology of the maxillary molars.

Single roots and single canals, which are rare abnormalities for the first molars [5], were found in $0.49 \%$ of the upper first molars and in $0.74 \%$ of the second molars. Their presence appears to be relatively uncommon, which is corresponding to observations revealed in previous studies $[5,36]$.

During the $\mathrm{CBCT}$ images evaluation, a second molar fused with a supernumerary tooth was detected (Fig. 1). Fusion arises when two or more separate tooth buds merge at some stage of their development. Depending on the formation stage and the amount of available dentin, fusion can be partial or complete, resulting in a dysmorphic tooth with a fused crown and either joined or separate pulp chambers and canals [40]. Fusion is more prevalent in deciduous teeth, even if it may occur both in the deciduous and permanent dentition $[40,41]$. With incidence less than $1 \%$ in Caucasian population [42], fusion is predominantly found in incisors and canines but scarcely in molars [42, 43-45] Its bilateral occurrence is about ten times less common than unilateral one [43]. The frequency of fusion between permanent and supernumerary teeth is $0.1 \%$, and this type of fusion usually involves maxillary anterior teeth [45]. Clinically, this malformation leads to a dysmorphic shape with excessive mesiodistal tooth width. Especially in case of fusion between a regular tooth and a supernumerary tooth, more arch length is required causing spacing and alignment problems [46]. To our knowledge, little is known about the prevalence of maxillary second molars fusion with supernumerary teeth [47], except some case reports published over the past years, which are mainly focused on mandibular molars $[45,48,49]$. 
As mentioned before, even though CBCT imaging technology plays a significant role in the field of Endodontics, it cannot be routinely used in everyday clinical practice. The clinician should keep in mind that the patient is still exposed to ionizing radiation and ought to assess the relative risk. It is of vital importance for the patient the radiation exposure to be kept as low as judiciously feasible [50].

\section{CONCLUSION}

The present study showed that the Greek population has a higher prevalence of type III canal configurations according to Weine's classification in the mesio-buccal roots of maxillary molars. In addition, the incidence of the MB2 canal was significantly higher in first molars than in second molars.

To our knowledge, for the first time, we demonstrate the occurrence rate of rare morphologic variations such as maxillary first molars with a single root and a single canal and the fusion of a maxillary second molar with a supernumerary tooth in Greek population.

These morphological differences found in mesio-buccal roots may occur in ethnically divergent populations and should be taken into account by the clinician during surgical or nonsurgical endodontic procedures of the permanent maxillary molars.

It can be concluded that in vivo CBCT image's evaluation appears to be a noninvasive and clinically efficient tool in understanding the root morphology and root canal anatomy. The present findings could allocate the clinician pivotal information, on the grounds that meticulous knowledge of anatomic variations could result in the improvement of the outcomes of root canal treatment.

\section{CONFLICT OF INTEREST}

The authors confirm that this article content has no conflict of interest.

\section{ACKNOWLEDGEMENTS}

The authors gratefully acknowledge Dr. Mastoris M. for his generous and helpful contribution to this study.

\section{REFERENCES}

[1] Vertucci FJ. Root canal anatomy of the human permanent teeth. Oral Surg Oral Med Oral Pathol 1984; 58: 589-99.

[2] Slowey RR. Root canal anatomy. Road map to successful endodontics. Dent Clin North Am 1979; 23: 555-73.

[3] Vertucci FJ. Root canal morphology and its relationship to endodontic procedures. Endod Top 2005; 10: 3-29.

[4] Weine FS, Healey HJ, Gerstein H, Evanson L. Canal configuration in the mesiobuccal root of the maxillary first molar and its endodontic significance. Oral Surg Oral Med Oral Pathol 1969; 28: 41925.

[5] Cleghorn BM, Christie WH, Dong CC. Root and root canal morphology of the human permanent maxillary first molar: a literature review. J Endod 2006; 32: 813-21.

[6] Pecora JD, Woelfel JB, Sousa Neto MD, Issa IP. Morphologic study of the maxillary molars. Part II: internal anatomy. Braz Dent J 1992; 3: 53-7.

[7] Sert S, Bayirli GS. Evaluation of the root canal configurations of the mandibular and maxillary permanent teeth by gender in the Turkish population. J Endod 2004; 30: 391-8.
[8] Ferguson DB, Kjar KS, Hartwell GR. Three canals in the mesiobuccal root of a maxillary first molar: a case report. J Endod 2005; 31: 400-2.

[9] Christie WH, Pekoff MD, Fugel HM. Maxillary molar with two palatal root a retrospective clinical study. J Endod 1991; 17: 80-4.

[10] Badole GP, Bahadure RN, Warhadpande MM, Kubde R. A rare root canal configuration of maxillary second molar: a case report. Case Rep Dent 2012; 2012: 767582.

[11] De Moor RJ. C-shaped root canal configuration in maxillary first molars. Int Endod J 2002; 35: 200-8.

[12] Carns EJ, Skidmore AE, Morgantown W. Configurations and deviations of root canals of maxillary first premolars. Oral Surg 1973; 36: 880-6.

[13] Barker BCW, Lockett BC, Parsons KC. The demonstrations of root canal anatomy. Aust Dent J 1969; 14: 37-41

[14] Ross F, Evanchik PA. Root fusion in molars: incidence and sex linkage. J Periodontol 1981; 52: 663-7.

[15] Kaffe I, Kaufman A, Littner MM, Lazarson A. Radiographic study of the root canal system of mandibular anterior teeth. Int Endod J 1985; 18: 253-9.

[16] Pineda F. Roentgenographic investigation of the mesiobuccal root of the maxillary first molar. Oral Surg Oral Med Oral Pathol 1973; 36: 253-60.

[17] Buhrley LJ, Barrows MJ, BeGole EA, Wenckus CS. Effect of magnification on locating the MB2 canal in maxillary molars. J Endod 2002; 28: 324-7.

[18] Stropko JJ. Canal morphology of maxillary molars: clinical observations of canal configurations. J Endod 1999; 25: 446-50.

[19] Patel S, Dawood A, Pitt Ford T, Whaites E. The potential applications of cone beam computed tomography in the management of endodontic problems. Int Endod J 2007; 40: 818-30.

[20] Cotton TP, Geisler TM, Holden DT, Schwartz SA, Schindler WG. Endodontic applications of cone beam volumetric tomography. J Endod 2007; 33: 1121-32.

[21] Weine FS. Endodontic Therapy. $4^{\text {th }}$ ed. St. Louis, MO: Mosby 1989; pp. 222-3.

[22] Estrela C, Bueno MR, Leles CR, Azevedo B, Azevedo JR. Accuracy of cone beam computed tomography and panoramic radiography for the detection of apical periodontitis. J Endod 2008; 34: 273-9.

[23] Nakata K, Naitoh M, Izumi M, Inamoto K, Ariji E, Nakamura H. Effectiveness of dental computed tomography in diagnostic imaging of periradicular lesion of each root of a multi-rooted tooth: case report. J Endod 2006; 32: 583-7.

[24] Cohenca N, Simon JH, Roges R, Morag Y, Malfaz JM. Clinical indications for digital imaging in dento-alveolar trauma. Part 1: traumatic injuries. Dent Traumatol 2007; 23: 95-104.

[25] Bernardes RA, de Moraes IG, Húngaro Duarte MA, Azevedo BC, de Azevedo JR, Bramante CM. Use of cone beam volumetric tomography in the diagnosis of root fractures. Oral Surg Oral Med Oral Pathol Oral Radiol Endod 2009; 108: 270-7.

[26] Bhuva B, Barnes JJ, Patel S. The use of limited cone beam computed tomography in the diagnosis and management of a case of perforating internal root resorption. Int Endod J 2011; 44: 777-86.

[27] Blattner TC, George N, Lee CC, Kumar V, Yelton CD. Efficacy of cone beam computed tomography as a modality to accurately identify the presence of second mesiobuccal canals in maxillary first and second molars: a pilot study. J Endod 2010; 36: 867-70.

[28] Domark JD, Hatton JF, Benison RP, Hildebolt CF. An ex vivo comparison of digital radiography and cone-beam and micro computed tomography in the detection of the number of canals in the mesiobuccal roots of maxillary molars. J Endod 2014; 39: 901- 5.

[29] Alavi AM, Opasanon A, Ng YL,Gulabivala K. Root and canal morphology of Thai maxillary molars. Int Endod J 2002; 35: 47885.

[30] Ng YL, Aung TH, Alavi A, Gulabivala K. Root and canal morphology of Burmese maxillary molars. Int Endod J 2001; 34: 62030 .

[31] Sykaras S, Economou P. Root canal morphology of the mesiobuccal root of the maxillary first molar. Oral Res Abstr 1971; 2025

[32] Lee JH, Kim KD, Lee JK, et al. Mesiobuccal root canal anatomy of Korean maxillary first and second molars by cone-beam computed tomography. Oral Surg Oral Med Oral Pathol Oral Radiol Endod 2011; 111: 785-91.

[33] Neelakantan P, Subbarao C, Ahuja R, Subbarao CV, Gutmann JL. Cone-beam computed tomography study of root and canal mor- 
phology of maxillary first and second molars in an Indian population. J Endod 2010; 36: 1622-7.

[34] Zheng QH, Wang Y, Zhou XD, Wang Q, Zeng G, Huang D. A cone-beam computed tomography study of maxillary first permanent molar root and canal morphology in a Chinese population. $\mathrm{J}$ Endod 2010; 36: 1480-4.

[35] Zhang R, Yang H, Yu X, Dummer PMH. Use of CBCT to identify the morphology of maxillary permanent molar teeth in a Chinese subpopulation. Int Endod J 2010; 44: 162-9.

[36] Kim Y, Lee SJ, Woo J. Morphology of maxillary first and second molars analyzed by cone-beam computed tomography in a Korean population: variations in the number of roots and canals and the incidence of fusion. J Endod 2012; 38: 1063-8.

[37] Silva EJ, Nejaim Y, Silva AI, Haiter-Neto F, Zaia AA, Cohenca N. Evaluation of root canal configuration of maxillary molars in a Brazilian population using cone-beam computed tomographic imaging: an in vivo study. J Endod 2014; 40: 173-6.

[38] Rwenyonyi CM, Kutesa AM, Muwazi LM, Buwembo W. Root and canal morphology of maxillary first and second permanent molars teeth in a Ugandan population. Int Endod J 2007; 40: 679-83.

[39] al Shalabi RM, Omer OE, Glennon J, Jennings M, Claffey NM. Root canal anatomy of maxillary first and second permanent molars. Int Endod J 2000; 33: 405-14.

[40] Shafer WG, Hine MK, Levy BM. Developmental disturbances of oral and paraoral structures. In: Saunders WB, Ed. A text book of oral pathology, $4^{\text {th }}$ ed. Philadelphia, PA 1993: pp. 38-9.
[41] Langlais RP, Miller CS. Dental abnormalities. In: Goucher J, Ed. Color atlas of common oral diseases, $3^{\text {rd }}$ ed. Baltimore: Lippincott Williams and Wilkins 2003: p. 74.

[42] Levitas TC. Gemination, fusion, twinning, and concrescence. J Dent Children 1965; 32: 93-100.

[43] Brook AH, Winter GB. Double teeth. A retrospective study of 'geminated' and 'fused' teeth in children. Br Dent J 1970 4; 129: 123-30.

[44] Grimanis GA, Kyriakides AT, Spyropoulos ND. A survey on supernumerary molars. Quintessence Int 1991; 22: 989-95.

[45] Nunes E, de Moraes IG, Novaes PMO, de Sousa SMG. Bilateral fusion of mandibular second molars with supernumerary teeth: case report. Braz Dent J 2002; 13: 137- 41.

[46] Hiilsmann M, Bahr R, Grohmanii U. Hemisection and vital treatment of a fused tooth literature review and ease report. Endod Dent Traumatol 1997; 13: 253- 8

[47] Narayanan KS. Endodontic management of supernumerary tooth fused with maxillary second molar. J Orofac Sci 2013; 5: 47-9.

[48] Beltes P, Huang G. Endodontic treatment of an unusual mandibular second molar. Endod Dent Traumatol 1997; 13: 96-8.

[49] Rudagi K, Rudagi BM, Metgud S, Wagle R. Endodontic management of mandibular second molar fused to a supernumerary tooth, using spiral computed tomography as a diagnostic aid: a case report. Case Reports in Dentistry 2012; vol. 2012: 1-5. Article ID 614129.

[50] White SC, Pharoah MJ. Oral radiology: principles and interpretation. $6^{\text {th }}$ ed. St. Louis: Mosby/Elsevier 2009: p. 36

Received: December 05, 2014

Revised: December 28, 2014

Accepted: May 05, 2015

(C) Nikoloudaki et al.; Licensee Bentham Open.

This is an open access article licensed under the terms of the Creative Commons Attribution Non-Commercial License (http://creativecommons.org/licenses/by-nc/3.0/) which permits unrestricted, non-commercial use, distribution and reproduction in any medium, provided the work is properly cited. 